ARTICLE

\title{
Product selectivity in plasmonic photocatalysis for carbon dioxide hydrogenation
}

Xiao Zhang ${ }^{1}$, Xueqian Li ${ }^{1}$, Du Zhang ${ }^{1}$, Neil Qiang Su${ }^{1}$, Weitao Yang ${ }^{1}$, Henry O. Everitt ${ }^{2,3}$ \& Jie Liu ${ }^{1}$

Photocatalysis has not found widespread industrial adoption, in spite of decades of active research, because the challenges associated with catalyst illumination and turnover outweigh the touted advantages of replacing heat with light. A demonstration that light can control product selectivity in complex chemical reactions could prove to be transformative. Here, we show how the recently demonstrated plasmonic behaviour of rhodium nanoparticles profoundly improves their already excellent catalytic properties by simultaneously reducing the activation energy and selectively producing a desired but kinetically unfavourable product for the important carbon dioxide hydrogenation reaction. Methane is almost exclusively produced when rhodium nanoparticles are mildly illuminated as hot electrons are injected into the anti-bonding orbital of a critical intermediate, while carbon monoxide and methane are equally produced without illumination. The reduced activation energy and super-linear dependence on light intensity cause the unheated photocatalytic methane production rate to exceed the thermocatalytic rate at $350^{\circ} \mathrm{C}$.

\footnotetext{
${ }^{1}$ Department of Chemistry, Duke University, Durham, North Carolina 27708, USA. ${ }^{2}$ Department of Physics, Duke University, Durham, North Carolina 27708 , USA. ${ }^{3}$ Army Aviation \& Missile RD\&E Center, Redstone Arsenal, Alabama 35898, USA. Correspondence and requests for materials should be addressed to H.O.E. (email: everitt@phy.duke.edu) or to J.L. (email: j.liu@duke.edu).
} 
T he societal need for industrial scale catalysis continues to grow in response to increasing demands for fertilizer, fuels and materials. For heterogeneous catalytic reactions with large activation energies to achieve practical rates, heated catalysts are used, but these demand high energy inputs, shorten catalyst lifetimes through sintering deterioration 1,2 , and require product selectivity to mitigate unfavourable side reactions. Rising atmospheric carbon dioxide $\left(\mathrm{CO}_{2}\right)$ concentrations may be reduced, for example, by reacting ambient $\mathrm{CO}_{2}$ with renewably generated hydrogen $\left(\mathrm{H}_{2}\right)^{3,4}$, but product selectivity is essential to ensure production of hydrocarbons such as methane $\left(\mathrm{CH}_{4}\right)$ instead of the kinetically preferred product carbon monoxide $(\mathrm{CO})^{5,6}$. Selective $\mathrm{CO}_{2}$ hydrogenation is also an essential purification step for the feedstock used in ammonia synthesis to fix nitrogen for fertilizers ${ }^{7}$. Ideal catalysts simultaneously lower operating temperatures, accelerate reaction rates, and preferentially select products without being consumed or altered. In spite of extensive research on the subject, no photocatalyst has yet achieved this lofty objective. Semiconductor-based photocatalysts offer a promising route to room temperature reactions $s^{8-10}$, but they exhibit limited selectivity ${ }^{11}$ and reaction rates that typically scale only as the square root of the light intensity $\left(R_{\text {photo }} \propto I^{0.5}\right)^{12,13}$, making it impractical to increase the reaction rate by increasing light intensity.

Recently, it has been discovered that plasmonic metal nanoparticles are photocatalytically active, ${ }^{14-29}$ driving chemical reactions with photo-generated hot carriers and exhibiting a compelling super-linear dependence on light intensity $\left(R_{\text {photo }} \propto I^{n}, n>1\right)^{18,28,30}$. Plasmonic metal nanoparticles are characterized by strong light absorption through excitations of collective free electron oscillations, called localized surface plasmon resonances (LSPRs) that may be spectrally tuned throughout the visible or ultraviolet by choice of metal, size, shape and host medium. Of particular interest is the decay of LSPRs into hot carriers and their subsequent transfer to adsorbates where they may affect reaction pathways and rates $^{31-34}$. The distribution of photoexcited carriers depends on the local density-of-states in the metal and the associated band structure, the LSPR of the nanostructure and the energy of the photon ${ }^{35}$. By tuning photon and LSPR energies so that hot carriers are injected into specific anti-bonding orbitals of specific reaction intermediates, product selectivity may be achieved $^{26,36,37}$.

These early demonstrations of plasmonic photocatalysis either featured intense laser pulses $\left(\sim \mathrm{kW} \mathrm{cm}{ }^{-2}\right)$ on nanoparticle clusters to generate high concentrations of hot carriers ${ }^{14,16-18}$, or they used alloyed or hybrid nanostructures composed of plasmonic (gold, silver, aluminium) and catalytic (platinum, cobalt, palladium) metals $\mathrm{s}^{20,21,26-28}$. The ideal photocatalytic metal should simultaneously exhibit good plasmonic and catalytic behaviors to increase the rates and selectivity of the reaction ${ }^{25}$. Recently, the size- and shape-dependent plasmonic properties of rhodium (Rh) nanoparticles have been demonstrated at energies tunable throughout the ultraviolet and visible regions ${ }^{38-43}$. Like $\mathrm{Au}$ and $\mathrm{Pt}, \mathrm{Rh}$ is a transition metal without a native oxide coating, and direct bonding between adsorbates and the metal surface greatly facilitates the transfer of hot carriers for plasmonic photocatalysis. Supported Rh nanoparticles and molecular complexes are widely used as catalysts in automotive catalytic converters to reduce nitrogen oxides, as well as in industrial hydrogenation, hydroformylation, and ammonia oxidation reactions ${ }^{44-46}$.

Here, we report the discovery that plasmonic Rh nanoparticles are photocatalytic, simultaneously lowering activation energies and exhibiting strong product photo-selectivity, as illustrated through the $\mathrm{CO}_{2}$ hydrogenation reaction. $\mathrm{CO}_{2}$ hydrogenation on transition metals at atmospheric pressure proceeds through two competing pathways: $\mathrm{CO}_{2}$ methanation $\left(\mathrm{CO}_{2}+4 \mathrm{H}_{2} \rightarrow \mathrm{CH}_{4}+\right.$ $2 \mathrm{H}_{2} \mathrm{O}$ ) and reverse water gas shift (RWGS, $\mathrm{CO}_{2}+\mathrm{H}_{2} \rightarrow \mathrm{CO}+$ $\left.\mathrm{H}_{2} \mathrm{O}\right)^{47}$. We observe that mild illumination of the $\mathrm{Rh}$ nanoparticles not only reduces activation energies for $\mathrm{CO}_{2}$ hydrogenation $\sim 35 \%$ below thermal activation energies, it also produces a strong selectivity towards $\mathrm{CH}_{4}$ over $\mathrm{CO}$. Specifically, under illumination from low-intensity $\left(\sim \mathrm{W} \mathrm{cm}{ }^{-2}\right)$, continuous wave blue or ultraviolet light-emitting diodes (LEDs), the photocatalytic reactions on unheated $\mathrm{Rh}$ nanoparticles produce $\mathrm{CH}_{4}$ with selectivity of $>86 \%$ or $>98 \%$, respectively, with a reaction rate twice that of the thermocatalytic reaction rate at $623 \mathrm{~K}\left(350{ }^{\circ} \mathrm{C}\right)$. This high selectivity towards $\mathrm{CH}_{4}$ disappears when the $\mathrm{Rh}$ nanoparticles are not illuminated, in stark contrast to plasmonic gold $(\mathrm{Au})$ nanoparticles that only catalyse $\mathrm{CO}$ production whether illuminated or not. Density functional theory (DFT) calculations indicate the photo-selectivity of the $\mathrm{Rh}$ photocatalyst can be attributed to the alignment of the hot electron distribution with the anti-bonding orbital of the critical reaction intermediate, $\mathrm{CHO}$, which activates the $\mathrm{CO}_{2}$ methanation pathway. Our discovery that plasmonic $\mathrm{Rh}$ nanoparticles exhibit a photocatalytic activity with strong product photoselectivity opens an exciting new pathway in the long history of heterogeneous catalysis by offering a compelling advantage of light over heat.

\section{Results}

Photocatalytic and thermocatalytic reactions. The $\mathrm{Rh}$ photocatalyst was prepared by dispersing $37 \mathrm{~nm}$ Rh nanocubes on aluminium oxide $\left(\mathrm{Al}_{2} \mathrm{O}_{3}\right)$ nanoparticles with a mass loading of $1.02 \%\left(\mathrm{Rh} / \mathrm{Al}_{2} \mathrm{O}_{3}\right.$, Fig. 1a) ${ }^{38}$. The synthetic method used (see 'Methods' section) produces cubic nanoparticles whose size and LSPR wavelength can be precisely tuned, and whose sharp corners concentrate light and liberate hot carriers ${ }^{48}$. For these experiments, the $334 \mathrm{~nm}(3.71 \mathrm{eV})$ LSPR of the Rh nanocubes in ethanol is broadened and blue-shifted on a porous $\mathrm{Al}_{2} \mathrm{O}_{3}$ support but still overlapped our $365 \mathrm{~nm}(3.40 \mathrm{eV})$ ultraviolet light source (Fig. 1b; Supplementary Fig. 1). A blue LED $(460 \mathrm{~nm}, 2.70 \mathrm{eV}$ ) was also used to study the influence of excitation wavelength. The band structure of Rh (Supplementary Fig. 2) ${ }^{49}$ indicates that the ultraviolet and blue excitations avoid lower energy parasitic interband absorption and generate nearly free hot electrons with energies $2.5 \mathrm{eV}$ and $2.1 \mathrm{eV}$ above the Fermi level ${ }^{35,41}$, respectively. The Au photocatalyst was supported on an $\mathrm{Al}_{2} \mathrm{O}_{3}$ support with a mass loading of $1.70 \%\left(\mathrm{Au} / \mathrm{Al}_{2} \mathrm{O}_{3}\right)^{15,50}$. The $\mathrm{Au}$ nanoparticles have a spherical shape with an average diameter of $2.6 \mathrm{~nm}$ (Supplementary Fig. 3) and an LSPR near $517 \mathrm{~nm}(2.40 \mathrm{eV})$. A white LED $(400-800 \mathrm{~nm})$ was used for the Au photocatalyst, unless otherwise stated. Figure $1 \mathrm{~b}$ plots the strong absorption of the $\mathrm{Rh}$ and $\mathrm{Au}$ photocatalysts in the ultraviolet and visible regions, respectively, and their relationship with the emission spectra of the LEDs.

A fixed-bed reaction chamber equipped with a quartz window was used to carry out the photocatalytic reactions with controlled light illumination (Fig. 1e). The photocatalysts were packed with a thickness of $\sim 4 \mathrm{~mm}(\sim 15 \mathrm{mg})$ to ensure complete absorption of light. For the heated experiments, the temperature of the powder catalysts was precisely measured with a thermocouple and controlled by resistive heating and cooling water. However, the unheated 'ambient' experiments were initiated at room temperature and used no cooling water, so the temperature was allowed to rise and equilibrate. A mass spectrometer was connected to the chamber outlet for real-time, quantitative analysis of gaseous products. The conversion of $\mathrm{CO}_{2}$ was maintained $<5 \%$ to eliminate reactant-transport limitations and 
a

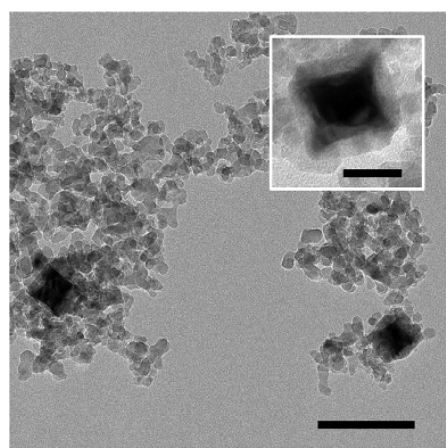

b



C



d

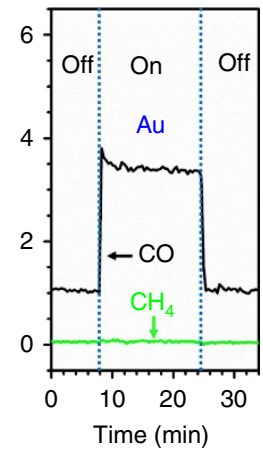

e

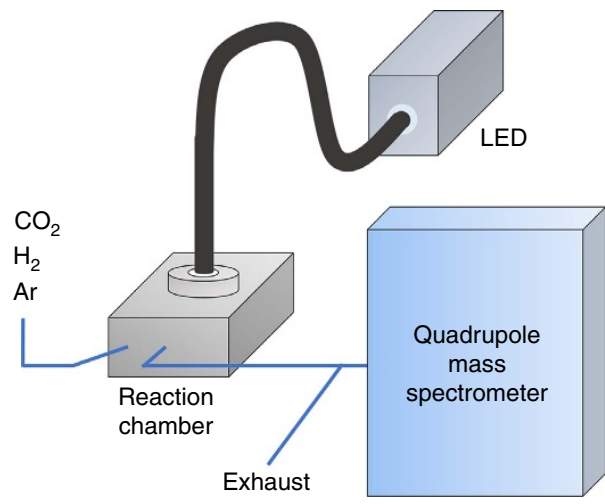

Figure 1 / $\mathbf{C O}_{\mathbf{2}}$ hydrogenation on the rhodium and gold photocatalysts. (a) TEM images of the $\mathrm{Rh} / \mathrm{Al}_{2} \mathrm{O}_{3}$ photocatalyst. Scale bar, $100 \mathrm{~nm}$ (inset: $25 \mathrm{~nm}$ ). (b) Ultraviolet-visible extinction spectra (solid lines) of the $\mathrm{Rh} / \mathrm{Al}_{2} \mathrm{O}_{3}$ (black) and $\mathrm{Au} / \mathrm{Al}_{2} \mathrm{O}_{3}$ (red) photocatalysts, measured by diffuse reflectance in an integrating sphere, overlaid with the emission spectra (dotted lines) of the ultraviolet (black), blue (blue) and white (red) LEDs. (c) Rates of $\mathrm{CH}_{4}$ (green) and $\mathrm{CO}$ (black) production at $623 \mathrm{~K}$ on $\mathrm{Rh} / \mathrm{Al}_{2} \mathrm{O}_{3}$ (solid lines) and $\mathrm{Al}_{2} \mathrm{O}_{3}$ (dotted lines) under dark and ultraviolet illumination at $3 \mathrm{~W} \mathrm{~cm}^{-2}$. $\mathrm{CH}_{4}$ production is strongly and selectively enhanced by ultraviolet light on the Rh photocatalyst. Neither $\mathrm{CH}_{4}$ nor $\mathrm{CO}$ production was detected on $\mathrm{Al}_{2} \mathrm{O}_{3}$. (d) Rates of $\mathrm{CO}$ (black) and $\mathrm{CH}_{4}$ (green) production at $623 \mathrm{~K}$ on $\mathrm{Au} / \mathrm{Al}_{2} \mathrm{O}_{3}$ under dark and white light illumination at $3 \mathrm{~W} \mathrm{~cm}{ }^{-2}$. A light-enhanced reaction rate is observed, but $\mathrm{CO}$ remains the exclusive product under both conditions. (e) Schematic of the photocatalytic reaction system, consisting of a stainless steel reaction chamber with a quartz window, LEDs coupled through a light guide, and a mass spectrometer for product analysis.

ensure that the concentrations of products in the effluent represent the reaction rates. In dark conditions, the reaction rates represent the thermocatalytic activities of the catalysts, while under illumination, the overall reaction rates are considered as the sum of thermo- and photocatalytic contributions. Thus, the photoreaction rates are obtained by subtracting the thermal reaction rates (light off) from the overall reaction rates (light on) at the same temperature. All reactions were performed at atmospheric pressure with either an $\mathrm{H}_{2}$-rich 1:5.5 or $\mathrm{H}_{2}$-deficient 1:3.1 mixture of $\mathrm{CO}_{2}: \mathrm{H}_{2}$ (as compared with the 1:4 stoichiometry of $\mathrm{CO}_{2}$ methanation) and argon (Ar) as an internal standard.

Selectivity. On the Rh photocatalyst (Fig. 1c, solid lines), $\mathrm{CH}_{4}$ and $\mathrm{CO}$ were produced at comparable rates at $623 \mathrm{~K}$ under dark, $\mathrm{H}_{2}$-rich conditions (for example, $0-8 \mathrm{~min}$ ). Upon illumination of ultraviolet light (for example, 8-22 min), a seven-fold increase in the $\mathrm{CH}_{4}$ production rate was observed, while only a slight increase in $\mathrm{CO}$ production was detected. No other carboncontaining product was observed above the detection limit of the mass spectrometer in our experiments, and the reaction rates responded to light instantly and reversibly. Control experiments using pure $\mathrm{Al}_{2} \mathrm{O}_{3}$ nanoparticles (Fig. 1c, dotted lines) and isotopic labelling experiments with deuterium (Supplementary Fig. 4) confirmed that $\mathrm{CH}_{4}$ and $\mathrm{CO}$ were produced from the photocatalytic reactions on the $\mathrm{Rh}$ nanocubes rather than from contaminants or the $\mathrm{Al}_{2} \mathrm{O}_{3}$ support. Comparable photo-enhanced
$\mathrm{CO}_{2}$ hydrogenation was also observed on the Au photocatalyst under white light illumination of similar intensity (Fig. 1d), but with distinctly different product selectivity: $\mathrm{CO}$ was the exclusive carbon-containing product on the Au photocatalyst under both dark and light conditions. Even under the same ultraviolet illumination as the $\mathrm{Rh}$ photocatalyst, $\mathrm{CO}$ was exclusively produced on the Au photocatalyst (Supplementary Fig. 5), indicating that wavelength alone cannot account for the different selectivity.

These results demonstrate that the different selectivity of thermo- and photocatalytic reactions on the $\mathrm{Rh}$ and $\mathrm{Au}$ nanoparticles is primarily determined by the properties of metals, specifically the differing metal-adsorbate interactions. On the Rh catalysts, previous experimental and theoretical investigations ${ }^{47,51-58}$ showed that $\mathrm{CO}_{2}$ first dissociatively adsorbs on the $\mathrm{Rh}$ surface to generate adsorbed $\mathrm{CO}$ and oxygen $(\mathrm{O})$. The adsorbed CO can either desorb from the surface or be hydrogenated to form $\mathrm{CHO}$. The dissociation of $\mathrm{CH}-\mathrm{O}$ generates $\mathrm{CH}$, followed by further hydrogenation to form $\mathrm{CH}_{4}$ (see Supplementary Fig. 6 for the detailed mechanism). The desorption of $\mathrm{CO}$ from the metal surface was identified as the rate-determining step (RDS) of $\mathrm{CO}$ production, and the dissociation of $\mathrm{CH}-\mathrm{O}$ was the RDS for $\mathrm{CH}_{4}$ production ${ }^{47}$. Thus, competition between $\mathrm{CO}$ desorption and $\mathrm{C}-\mathrm{O}$ bond cleavage in $\mathrm{CHO}$ dictates the product selectivity. The $\mathrm{O}$ adsorption energy, $E_{\mathrm{ads}, \mathrm{O}}$, on late transition-metal surfaces is known to be an effective descriptor of the selectivity of $\mathrm{CO}_{2}$ hydrogenation ${ }^{47}$. A high $E_{\text {ads,o }}$ partially compensates the energy cost for $\mathrm{C}-\mathrm{O}$ bond 
cleavage in the $\mathrm{CHO}$ intermediates and increases the selectivity towards $\mathrm{CH}_{4}$. Although the reaction on the Au catalysts has been reported to involve additional reaction intermediates ${ }^{22,59,60}$, the selectivity observed here is consistent with the corresponding $E_{\text {ads }, \mathrm{O}}$ of $\mathrm{Rh}(5.22 \mathrm{eV})$ and $\mathrm{Au}(3.25 \mathrm{eV})^{61}$ : the Rh catalyst had a slight preference towards $\mathrm{CH}_{4}$ production under dark conditions, whereas the $\mathrm{Au}$ catalyst exclusively produced $\mathrm{CO}$.

The selectivity of these reactions is changed when hot carriers are photoexcited in plasmonic nanoparticles. The different selectivity of thermo- and photo-reactions on $\mathrm{Rh}$ nanoparticles is depicted in Fig. 2a,b. The dark thermocatalytic reaction exhibited mild selectivity, with a $\mathrm{CH}_{4}$ : $\mathrm{CO}$ ratio of $\sim 60: 40$ in the tested range of temperatures and reaction rates. In contrast, under ultraviolet illumination the $\mathrm{CH}_{4}$ production rate was significantly and selectively enhanced. The photoreactions exhibit $>95 \%$ selectivity towards $\mathrm{CH}_{4}$, and the resulting selectivity towards $\mathrm{CH}_{4}$ from the overall reaction is $>90 \%$ under $3 \mathrm{~W} \mathrm{~cm}^{-2}$ ultraviolet illumination and $\mathrm{H}_{2}$-rich conditions over the tested temperature range. Experiments under $\mathrm{H}_{2}$-deficient conditions maintained this high selectivity under illumination but exhibited even lower selectivity under dark conditions, confirming that illumination, not heat or excess $\mathrm{H}_{2}$ feedstock, is responsible for the highly selective production of $\mathrm{CH}_{4}$ (Fig. 2b). The $\mathrm{Rh}$ nanoparticles and the porous $\mathrm{Al}_{2} \mathrm{O}_{3}$ support are in excellent thermal equilibrium with each other $(\Delta T \ll 1 \mathrm{~K}$, Supplementary Note 1 and refs 62,63$)$ because of their physical contact and high thermal conductivities. The rather modest local heating in our experiments and the observed high photo-selectivity towards $\mathrm{CH}_{4}$ over $\mathrm{CO}$ indicate that the photo-enhanced reaction rates do not originate from thermal or plasmonic photothermal heating on the $\mathrm{Rh}$ nanoparticle surface. Instead, it is the plasmon-generated hot electrons that selectively activate $\mathrm{CHO}$ intermediates and accelerate $\mathrm{CH}_{4}$ production while minimally affecting the CO-metal bond for CO production (desorption). This analysis is based on the assumption that thermo- and photo-reactions have the same elementary steps and surface intermediates, a claim supported by a recent kinetic study of RWGS on Au photocatalysts ${ }^{22}$. Although the selectivity is derived almost entirely from light, heat significantly increases the reaction rate.

For the ambient experiments, efficient photocatalytic $\mathrm{CH}_{4}$ production with high selectivity was demonstrated on $\mathrm{Rh}$ under ultraviolet illumination at $3 \mathrm{~W} \mathrm{~cm}^{-2}$ and $\mathrm{H}_{2}$-rich conditions with a reaction rate (circled red square in Fig. 2d) comparable to the thermocatalytic reaction rate at $548 \mathrm{~K}\left(275^{\circ} \mathrm{C}\right)$. The slightly elevated steady-state temperature, measured to be $328 \mathrm{~K}(\Delta T=29$ $\mathrm{K})$, was caused by photothermal heating of the catalyst bed (separately measured to be $25 \mathrm{~K}$ by a non-reactive control experiment with flowing $\mathrm{Ar}$ and $\mathrm{H}_{2}$ ) and the exothermic nature
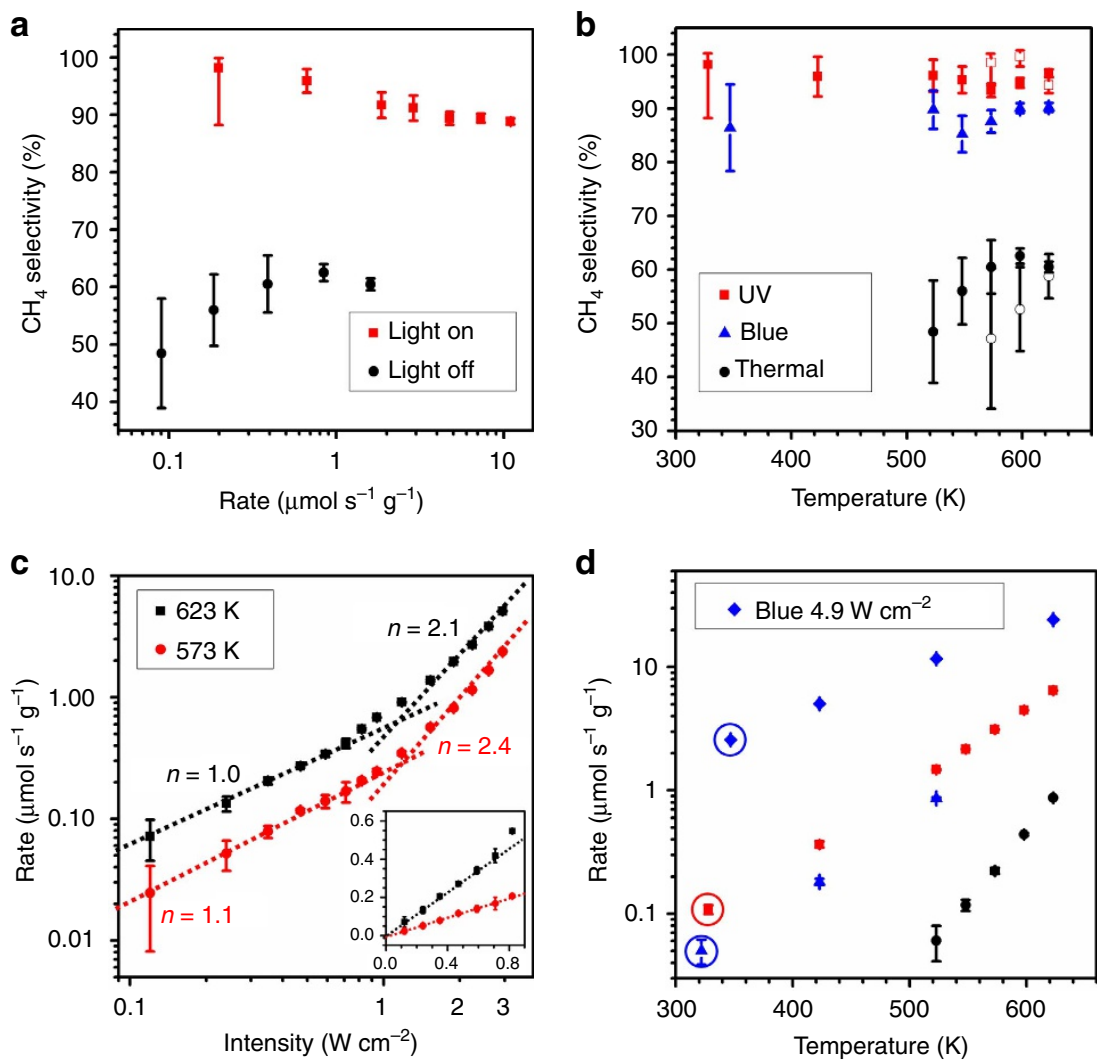

Figure 2 | Product selectivity and reaction rates on the rhodium photocatalyst. (a) Selectivity towards $\mathrm{CH}_{4}$ as a function of overall reaction rates in dark (black circles) and under ultraviolet light at $3 \mathrm{~W} \mathrm{~cm}^{-2}$ (red squares). (b) Selectivity towards $\mathrm{CH}_{4}$ of the thermo- (black circles) and photocatalytic reactions under ultraviolet $\left(365 \mathrm{~nm}\right.$, red squares) and blue $\left(460 \mathrm{~nm}\right.$, blue triangles) illumination as a function of temperature under $\mathrm{H}_{2}-$ rich $\left(\mathrm{CO}_{2}: \mathrm{H}_{2}=1: 5.5\right.$, solid symbols) and $\mathrm{H}_{2}$-deficient $\left(\mathrm{CO}_{2}: \mathrm{H}_{2}=1: 3.1\right.$, open symbols) conditions. The photoreaction rates are calculated by subtracting the thermocatalytic reaction rates from overall reaction rates at the same temperature. The photoreactions under ultraviolet light show higher selectivity towards $\mathrm{CH}_{4}$ than under blue light, which are both much higher than that of the thermocatalytic reaction. (c) Rates of $\mathrm{CH}_{4}$ photo-production as a function of ultraviolet light intensity at 623 (black squares) and $573 \mathrm{~K}$ (red circles). The intensity-dependent reaction rates show a linear to super-linear transition with increasing light intensity. The inset shows the intensity-dependent reaction rates in the linear region. (d) Overall, $\mathrm{CH}_{4}$ production rates in dark (black circles) and under ultraviolet (red squares, $3 \mathrm{Wcm}^{-2}$ ) and blue (blue triangles, $2.4 \mathrm{~W} \mathrm{~cm}^{-2}$ ) LEDs with the same photon flux, and with twice the blue photon flux (blue diamonds, $4.9 \mathrm{~W} \mathrm{~cm}^{-2}$ ). Ultraviolet light is more efficient at enhancing the reaction rates than blue light with the same photon flux. Circled points show the unheated steady-state temperatures and reaction rates. Error bars represent the s.d. of measurements by the mass spectrometer. 
of the $\mathrm{CO}_{2}$ methanation reaction $\left(4 \mathrm{~K}, \Delta H^{0}=-165.01 \mathrm{~kJ} \mathrm{~mol}^{-1}\right.$ at $298 \mathrm{~K}$ ). Likewise, the ambient reaction rate for the highest intensity of our blue LED $\left(4.9 \mathrm{~W} \mathrm{~cm}^{-2}, \Delta T=48 \mathrm{~K}\right.$, circled blue diamonds in Fig. 2d) was two times higher than that of the thermocatalytic reaction rate at $623 \mathrm{~K}\left(350^{\circ} \mathrm{C}\right)$ with a quantum yield, defined as the molar ratio of methane generated to photons delivered (Supplementary Note 2), of $0.82 \%$. It is important to recognize that these high reaction rates with high selectivity were achieved using an efficient, low-intensity LED.

\section{Discussion}

The effects of LED intensity and photon energy on the reaction rates using the $\mathrm{Rh}$ photocatalyst were carefully studied by varying the output power and wavelength of the light source. Under ultraviolet illumination near $\sim 1 \mathrm{~W} \mathrm{~cm}{ }^{-2}$, the photoreaction rate under $\mathrm{H}_{2}$-rich conditions changed from a linear to a super-linear dependence on light intensity $\left(R_{\text {photo }} \propto I^{n}, n=2.1\right.$ at $623 \mathrm{~K}$ and 2.4 at $573 \mathrm{~K}$, Fig. 2c). This super-linear relationship confirms that the photoreactions are mediated by hot electrons ${ }^{18}$ and can be attributed to multiple excitations of the vibrational mode(s) of the adsorbed RDS intermediate by hot electrons ${ }^{30}$. In the lowintensity linear region, the slope is significantly higher at $623 \mathrm{~K}$ than at $573 \mathrm{~K}$ (Fig. 2c, inset) as heat accelerates the photocatalytic rate. Conversely, the photocatalytic reaction rates were greatly enhanced at the highest intensity of the ultraviolet LED $\left(3 \mathrm{~W} \mathrm{~cm}^{-2}\right.$, red squares in Fig. 2d), compared with the thermocatalytic reaction rates at the same temperature. The enhancement factor for $\mathrm{CH}_{4}$ production $\left(\mathrm{EF}=R_{\text {overall }} / R_{\text {thermal }}\right)$ was $7.41 \pm 0.37$ at $623 \mathrm{~K}$ and increased to $24.4 \pm 1.2$ at $523 \mathrm{~K}$. The quantum yield for $\mathrm{CH}_{4}$ production was measured to be $3.70 \%$ at $623 \mathrm{~K}$.

Under illumination from the blue LED with the same photon flux $\left(2.4 \mathrm{~W} \mathrm{~cm}^{-2}\right)$ as the ultraviolet LED at $3 \mathrm{~W} \mathrm{~cm}^{-2}$, the reaction rate and quantum yield were smaller (blue triangles in Fig. 2d). Nevertheless, the reaction rate under lower energy photons exhibits an even higher exponent in the super-linear region $(n \approx 3.7 \text { at } 523 \mathrm{~K})^{30}$. At the highest intensity of the blue LED $\left(4.9 \mathrm{~W} \mathrm{~cm}^{-2}\right)$, the EF and quantum yield at $623 \mathrm{~K}$ reached $27.8 \pm 1.4$ and $7.50 \%$, respectively (blue diamonds in Fig. $2 \mathrm{~d}$ ). Unlike the sub-linear rate increase with increased light intensity characteristic of conventional semiconductor photocatalysis ${ }^{12,13}$, this super-linear dependence indicates that very high reaction rates will not require very high light intensities.

To understand the mechanism, the reaction kinetics of $\mathrm{CO}_{2}$ hydrogenation on $\mathrm{Rh}$ and $\mathrm{Au}$ photocatalysts in light and dark $\mathrm{H}_{2}$-rich conditions were studied experimentally in the temperature range of $523 \mathrm{~K}$ and $623 \mathrm{~K}$. The light intensity was chosen to be within the linear region to eliminate the effect of multiple excitation events. By fitting the measured temperature-dependent reaction rates with an Arrhenius equation, the apparent activation energy $\left(E_{\mathrm{a}}\right)$ of the thermo- and photo-reactions was obtained (Fig. 3). In virtually every case, the equation fits the data well, and the $E_{\mathrm{a}}$ was ascertained with less than $5 \%$ uncertainty. For the thermocatalytic reactions on $\mathrm{Rh}$, the $E_{\mathrm{a}}$ for $\mathrm{CH}_{4}$ and $\mathrm{CO}$ production was measured to be $78.6 \pm 2$ and $64.7 \pm 6 \mathrm{~kJ} \mathrm{~mol}^{-1}$
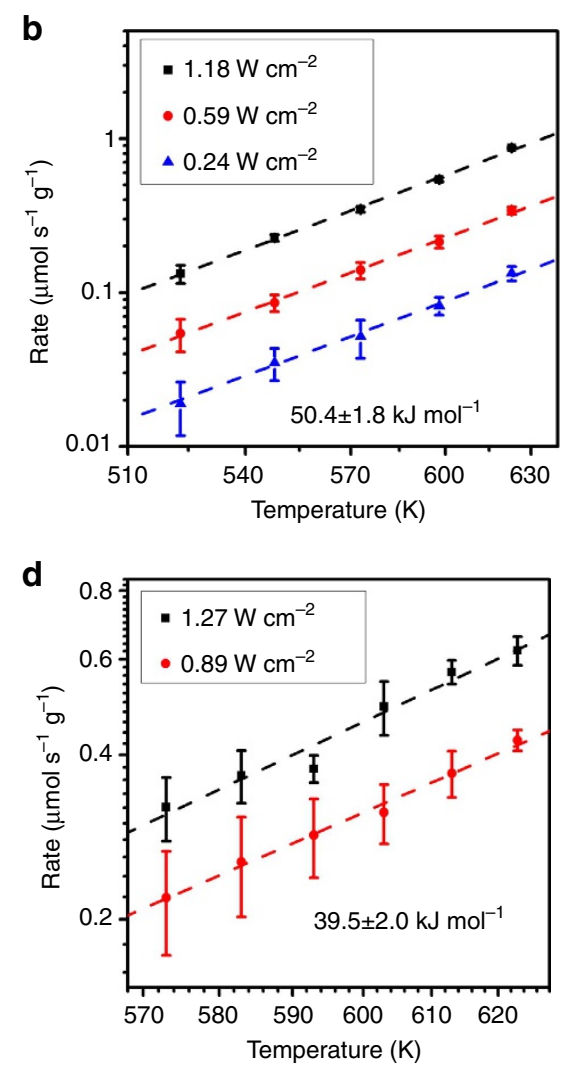

Figure 3 | Apparent activation energies on the rhodium and gold photocatalysts. (a) Thermocatalytic reaction rates of $\mathrm{CH}_{4}$ (black squares) and $\mathrm{CO}$ (red circles) production on $\mathrm{Rh} / \mathrm{Al}_{2} \mathrm{O}_{3}$ as a function of temperature. The apparent activation energies are obtained by fitting the results with an Arrhenius equation. (b) Photoreaction rates for $\mathrm{CH}_{4}$ production on $\mathrm{Rh} / \mathrm{Al}_{2} \mathrm{O}_{3}$ under 1.18 (black squares), 0.59 (red circles) and $0.24 \mathrm{~W} \mathrm{~cm}^{-2}$ (blue triangles) ultraviolet illumination as a function of temperature. The photocatalytic reactions show the same apparent activation energy, which is lower than that of thermocatalytic reaction. (c) Thermocatalytic reaction rates of $\mathrm{CO}$ production on $\mathrm{Au} / \mathrm{Al}_{2} \mathrm{O}_{3}$ as a function of temperature. (d) Photoreaction rates of $\mathrm{CO}$ production on $\mathrm{Au} / \mathrm{Al}_{2} \mathrm{O}_{3}$ under 1.27 (black squares) and $0.89 \mathrm{Wcm}^{-2}$ (red circles) white light as a function of temperature. Reduced apparent activation energies of photoreactions are observed on both Rh and Au photocatalysts, but with different selectivity. Error bars represent the s.d. of measurements by the mass spectrometer. 
$(0.81 \mathrm{eV}$ and $0.67 \mathrm{eV})$, respectively, consistent with previous reports on supported $\mathrm{Rh}$ catalysts ${ }^{51,64}$. Under ultraviolet illumination, the photocatalytic $\mathrm{CH}_{4}$ production showed a reduced $E_{\mathrm{a}}=50.4 \pm 1.8 \mathrm{~kJ} \mathrm{~mol}^{-1}(0.52 \mathrm{eV})$ for all light intensities. This reduction of $E_{\mathrm{a}}$ was also observed for $\mathrm{CO}$ production on the $\mathrm{Au}$ photocatalyst with visible light, decreasing from $55.8 \pm 0.5 \mathrm{~kJ} \mathrm{~mol}^{-1}(0.58 \mathrm{eV})$ for the thermocatalytic reaction to $39.5 \pm 2 \mathrm{~kJ} \mathrm{~mol}^{-1}(0.41 \mathrm{eV})$ for photoreactions. The photoreaction rates of $\mathrm{CO}$ production on the $\mathrm{Rh}$ photocatalyst were too small for the activation energy to be deduced reliably.

The observed kinetics and selectivity of $\mathrm{CO}_{2}$ hydrogenation on the $\mathrm{Rh}$ and $\mathrm{Au}$ photocatalysts shed light on the reaction mechanism of plasmonic photocatalysis. In thermocatalytic reactions, interactions between surface intermediates and catalysts dictate the propensity of competing pathways. For example, the higher selectivity towards $\mathrm{CH}_{4}$ in the thermocatalytic reactions on $\mathrm{Rh}$ has already been ascribed to its higher $E_{\mathrm{ads}, \mathrm{O}}$ (ref. 61), while the exclusive selectivity for $\mathrm{CO}$ on the $\mathrm{Au}$ photocatalyst was caused by the low $E_{\text {ads, } O}$ and the deficiency of surface $\mathrm{H}$ atoms under our experimental conditions ${ }^{65}$. By contrast, in photoreactions, the transfer of hot electrons from plasmonic metal nanoparticles to specific intermediates critically depends on the energies of the hot electrons and the anti-bonding orbitals, thereby selectively activating certain reaction pathways and offering an additional means to tune the selectivity $23,24,37$.

DFT calculations were carried out to understand how hot electrons affect the intermediates in the RDSs of $\mathrm{CH}_{4}$ and $\mathrm{CO}$ production and explain the photo-selectivity we observed. The projected local density-of-states (LDOS) for adsorbed $\mathrm{CHO}$ and

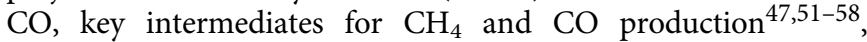
respectively, are presented in Fig. $4 \mathrm{a}, \mathrm{b}$ for the dominant $\mathrm{Rh}$ nanocube facet, $\mathrm{Rh}(100)$ (see 'Methods' section for details and Supplementary Fig. 7 for the configurations used in calculations). For clarity, only the orbitals involved in $\mathrm{C}-\mathrm{O}$ bond cleavage for the $\mathrm{Rh}-\mathrm{CHO}$ system and $\mathrm{Rh}-\mathrm{C}$ bond cleavage for the $\mathrm{Rh}-\mathrm{CO}$ system are plotted. The bonding interactions in both the $\mathrm{CHO}$ and $\mathrm{CO}$ systems lie $\sim 6 \mathrm{eV}$ below the Fermi level, suggesting a minimal role of hot holes in this process. For $\mathrm{CHO}$, the $\mathrm{C}-\mathrm{O} \pi^{*}$ anti-bonding bands, which can accept hot electrons to weaken the $\mathrm{C}-\mathrm{O}$ bond and facilitate $\mathrm{CH}_{4}$ production, can be easily identified on the $\mathrm{C}\left(p_{z}\right)$ and $\mathrm{O}\left(p_{z}\right)$ orbitals at $\sim 2 \mathrm{eV}$ (Fig. $4 \mathrm{a}$ ). On the other hand, the very weak and broad anti-bonding $\mathrm{Rh}-\mathrm{C}$ interactions observed on the $\mathrm{C}\left(p_{x}\right)$ orbital at $\sim 1 \mathrm{eV}$ for $\mathrm{CO}$ (Fig. $4 \mathrm{~b}$ ) suggests a much smaller possibility of accepting ultraviolet photoexcited hot electrons by the $\mathrm{CO}$ intermediate compared with the $\mathrm{CHO}$ intermediate. Thus, the photo-generated hot electrons preferentially activated the $\mathrm{CHO}$ intermediate and enhanced $\mathrm{CH}_{4}$ production, while only a small enhancement was observed for $\mathrm{CO}$ production. This mechanism is further verified by the lower selectivity towards $\mathrm{CH}_{4}$ observed under non-resonant, lower energy blue light ( $\sim 85 \%)$ : the lower energy hot electrons had a lower probability of transferring to the higher energy antibonding orbital of the $\mathrm{CHO}$ intermediate $(\sim 2 \mathrm{eV})$ and a higher probability of transferring to the lower energy orbital of the $\mathrm{CO}$ intermediate $(\sim 1 \mathrm{eV})$. We note that due to the rapid decay via electron-electron and electron-phonon scatterings, the actual energies of the hot electrons are distributed below the associated photon energies of ultraviolet and blue light. Nevertheless, our computed relative magnitude of the LDOS peaks and the energy ordering for the relevant anti-bonding bands still offer a valid qualitative interpretation both for overall preference for $\mathrm{CH}_{4}$ (under either ultraviolet or blue light) and for the slightly reduced $\mathrm{CH}_{4}$ selectivity under blue light. A recent study using alloys similarly demonstrated the selective activation of certain reactants with different photon energies ${ }^{26}$. Generally speaking, the activation of a specific reaction intermediate using the absorption of specific photon energies by specific plasmonic metal nanostructures can specify product selectivity among competing reaction pathways.

The deduced process of thermo- and photocatalytic $\mathrm{CO}_{2}$ hydrogenation on plasmonic Rh photocatalysts is summarized in Fig. 5. In the thermocatalytic reactions, phonons activate both $\mathrm{CHO}$ and $\mathrm{CO}$ intermediates and produce $\mathrm{CH}_{4}$ and $\mathrm{CO}$ at comparable rates on the ground-state reaction coordinate (black curve in the bottom part of Fig. 5). In the photocatalytic reactions, hot electrons selectively transfer to the anti-bonding orbitals of $\mathrm{CHO}$ intermediates to weaken the chemical bonds and drive the reaction on a charged-state reaction coordinate characterized by a reduced activation energy (red curve in the top part of Fig. 5). This scenario is consistent with similar schemes proposed for other reactions on plasmonic metal photocatalysts ${ }^{14-16,25,27}$. In the future, red-shifting the plasmonic resonance of $\mathrm{Rh}$ nanoparticles further into visible region, assembling $\mathrm{Rh}$ nanoparticles into closely packed clusters to create 'hot spots', and optimizing the reactant composition ${ }^{47}$ could achieve even more selective and
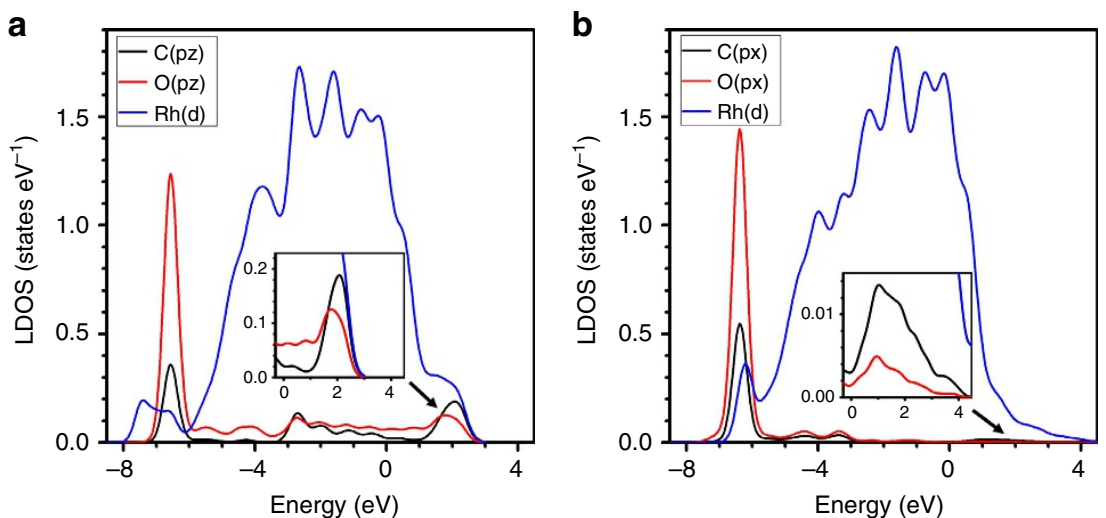

Figure 4 | DFT calculations of $\mathbf{C H O}$ and $\mathbf{C O}$ intermediates on the Rh(100) surface. (a) LDOS for adsorbed $\mathrm{CHO}$ on $\mathrm{C}\left(p_{z}\right), \mathrm{O}\left(p_{z}\right)$, and $\mathrm{Rh}(d)$ orbitals. The $\mathrm{Rh}(100)$ surface is perpendicular to the $x$ direction, and the $\mathrm{C}-\mathrm{O}$ bond is along the $y$ direction. Major bands are identified as: (1) $\mathrm{C}-\mathrm{O} \pi$ bonding band $\left(-6.5 \mathrm{eV}\right.$ ) with $\mathrm{C}\left(p_{z}\right)$ (black) and $\mathrm{O}\left(p_{z}\right)$ (red) interactions; (2) $\mathrm{C}-\mathrm{O} \pi^{\star}$ anti-bonding band $(1-3 \mathrm{eV}$, mode around $2 \mathrm{eV})$ with $\mathrm{C}\left(p_{\mathrm{z}}\right)$ and $\mathrm{O}\left(p_{\mathrm{z}}\right)$ interactions. (b) LDOS for adsorbed $\mathrm{CO}$ on $\mathrm{C}\left(p_{x}\right), \mathrm{O}\left(p_{x}\right)$, and $\mathrm{Rh}(d)$ orbitals. The $\mathrm{Rh}(100)$ surface is perpendicular to the $x$ direction, and the $\mathrm{C}-\mathrm{O}$ bond is along the $x$ direction. Major bands are identified as: (1) $\mathrm{C}-\mathrm{O} \sigma$ bonding band $\left(-6.3 \mathrm{eV}\right.$ ) with $\mathrm{C}\left(p_{x}\right)$ (black) and $\mathrm{O}\left(p_{x}\right)$ (red) interactions; (2) Very weak Rh-C antibonding band $\left(0-3 \mathrm{eV}\right.$, mode around $1 \mathrm{eV}$ ) with $\mathrm{C}\left(p_{x}\right)$ and $\mathrm{Rh}(d)$ (blue) interactions. The structures of the models used for calculations are given in Supplementary Fig. 7. All energies are referenced to the Fermi level. The insets are magnified plots of the anti-bonding regions. 


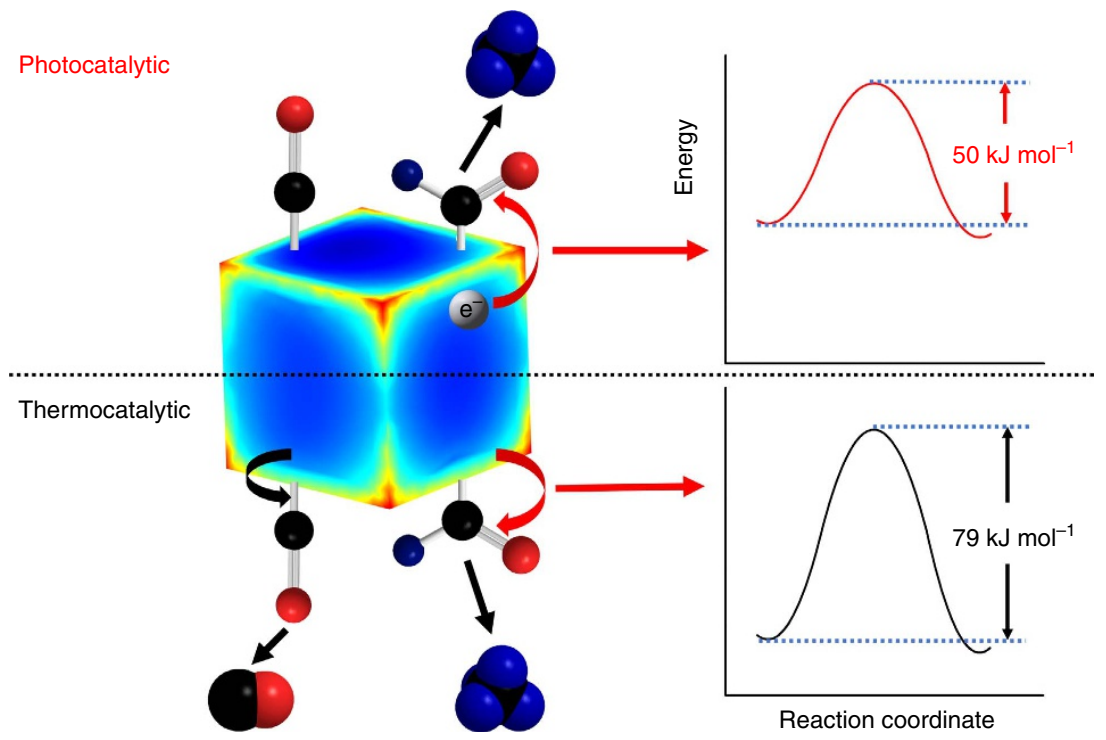

Figure 5 | Reaction mechanism on a rhodium nanocube. The thermocatalytic reaction activates both $\mathrm{CO}-\mathrm{Rh}$ bonds and $\mathrm{CH}-\mathrm{O}$ bonds to produce $\mathrm{CO}$ and $\mathrm{CH}_{4}$, respectively. Hot electrons generated in the photocatalytic reaction selectively activate the $\mathrm{C}-\mathrm{O}$ bonds of the $\mathrm{CHO}$ intermediate and reduce the apparent activation energy to enhance the $\mathrm{CH}_{4}$ production rate. The black, red, and blue spheres are carbon, oxygen, and hydrogen atoms, respectively. The red corners of the cube show the intense electric field from the excitation of $\mathrm{LSPRs}^{38}$

efficient photocatalytic $\mathrm{CH}_{4}$ production from $\mathrm{CO}_{2}$ hydrogenation, even under direct or mildly concentrated sunlight. Our findings demonstrate that efficient plasmonic photocatalysis requires metals with both excellent catalytic and plasmonic properties. Although the mechanism analysed is based on $\mathrm{CO}_{2}$ hydrogenation, the concept of selective activation of specific reaction intermediates to control the product selectivity can be applied to other plasmonic photocatalytic systems in ways that could prove to be transformative.

\section{Methods}

Photocatalyst preparation. $\mathrm{Rh} / \mathrm{Al}_{2} \mathrm{O}_{3}$ photocatalyst. The $\mathrm{Rh}$ nanocubes were synthesized by a modified slow-injection polyol method ${ }^{38}$. Overall, $54 \mathrm{mg}$ potassium bromide ( $\mathrm{KBr}, \mathrm{ACS}$, Acros) was dissolved in $2 \mathrm{ml}$ ethylene glycol (EG, J. T. Baker) in a $20 \mathrm{ml}$ glass vial and stirred in an oil bath at $160{ }^{\circ} \mathrm{C}$ for $1 \mathrm{~h}$. $12 \mathrm{mg}$ rhodium(III) chloride hydrate $\left(\mathrm{RhCl}_{3} \cdot x \mathrm{H}_{2} \mathrm{O}, 38 \% \mathrm{Rh}\right.$, Acros $)$ and $25 \mathrm{mg}$ polyvinylpyrrolidone (PVP, M.W. $\approx 55,000$, Aldrich) were dissolved in $2 \mathrm{ml} \mathrm{EG}$ separately and injected into the hot reaction mixture by a two-channel syringe pump at a rate of $1 \mathrm{ml} \mathrm{h}^{-1}$. The injection was paused for 15 min after adding $20 \mu \mathrm{l}$ of the Rh precursor. After complete injection of the precursor, the reaction mixture was stirred for another $30 \mathrm{~min}$ and then cooled to room temperature. The suspension was washed with deionized water/acetone until no $\mathrm{Cl}^{-}$and $\mathrm{Br}^{-}$was detected in the supernatant. The solid was dispersed in $20 \mathrm{ml}$ ethanol and impregnated on $90 \mathrm{mg} \mathrm{Al}_{2} \mathrm{O}_{3}$ nanoparticles (Degussa, Alu Oxide C, specific surface area $85-115 \mathrm{~m}^{2} \mathrm{~g}^{-1}$ ). The obtained solid was ground into powder and calcined in air at $400^{\circ} \mathrm{C}$ for $2 \mathrm{~h}$. The $\mathrm{Rh}$ nanocubes were well dispersed on the $\mathrm{Al}_{2} \mathrm{O}_{3}$ support and behaved as isolated nanoparticles.

$\mathrm{Au} / \mathrm{Al}_{2} \mathrm{O}_{3}$ photocatalyst. A deposition-precipitation method was used to prepare highly dispersed small $\mathrm{Au}$ nanoparticles on support ${ }^{15}$. Overall, $100 \mathrm{mg} \mathrm{Al}_{2} \mathrm{O}_{3}$ nanoparticles were dispersed in $10 \mathrm{ml}$ deionized water in a $20 \mathrm{~mL}$ glass vial by sonication. A total of $16 \mathrm{mg}$ gold(III) chloride trihydrate $\left(\mathrm{HAuCl}_{4} \cdot \mathrm{xH}_{2} \mathrm{O}\right.$, $99.9+\%$, Aldrich) was added into the suspension and stirred in an oil bath at $80^{\circ} \mathrm{C}$. The $\mathrm{pH}$ was adjusted to $\sim 8$ by $1 \mathrm{M}$ sodium hydroxide $(\mathrm{NaOH})$ solution. After $4 \mathrm{~h}$, the suspension was cooled and washed with copious deionized water/ acetone until no $\mathrm{Cl}^{-}$was detected in the supernatant. The solid was dried at $100^{\circ} \mathrm{C}$ overnight and calcined at $300^{\circ} \mathrm{C}$ for $2 \mathrm{~h}$.

Reactor setup and photocatalytic reactions. The photocatalytic reaction was carried out on a custom-built gaseous reaction system. Hydrogen $\left(\mathrm{H}_{2}\right.$, Research grade), carbon dioxide $\left(\mathrm{CO}_{2}\right.$, Research grade) and argon (Ar, UHP) were obtained from Airgas. The gas flow rates were controlled individually by mass flow controllers (Aalborg). Overall, $\sim 15 \mathrm{mg}$ of photocatalyst was loaded into the sample cup (diameter $6 \mathrm{~mm}$, height $4 \mathrm{~mm}$ ) in the reaction chamber (Harrick, HVCMRA-5) for each experiment. The temperature was measured by a thermocouple under the catalyst bed, and calculations indicate good thermal contact between the $\mathrm{Rh}$ nanoparticles and the surrounding media. The temperature of the photocatalyst bed was controlled by a PID temperature controller kit (Harrick, ATK-024-3) that managed the resistive heating power of the reaction chamber, and cooling water to mitigate heating caused by LED illumination. The photocatalysts were first reduced under $60.1 \mathrm{ml} \mathrm{min}^{-1} \mathrm{H}_{2}$ and $27.6 \mathrm{ml} \mathrm{min}^{-1} \mathrm{Ar}$ at $350^{\circ} \mathrm{C}$ for $4 \mathrm{~h}$ and then another $10.9 \mathrm{ml} \mathrm{min}{ }^{-1} \mathrm{CO}_{2}$ was introduced to achieve an $\mathrm{H}_{2}$-rich $\mathrm{CO}_{2}: \mathrm{H}_{2}$ ratio of $1: 5.5$ and activate the photocatalysts for $\sim 12 \mathrm{~h}$ to reach stable catalytic activities. The experiments with a $\mathrm{H}_{2}$-deficient $\mathrm{CO}_{2}: \mathrm{H}_{2}$ ratio of $1: 3.1$ were conducted under $19.5 \mathrm{ml} \mathrm{min}^{-1} \mathrm{CO}_{2}, 60.1 \mathrm{ml} \mathrm{min}^{-1} \mathrm{H}_{2}$ and $16.5 \mathrm{ml} \mathrm{min}^{-1} \mathrm{Ar}$. Three LEDs with emission of $365 \mathrm{~nm}, 460 \mathrm{~nm}$ and $5700 \mathrm{~K}$ white light (Prizmatix, UHP-F) were used as light sources. The output power was controlled by a remote dial and measured with a thermopile power metre (Thorlabs, PM310D). The emission spectra of the light sources were measured with a CCD-based spectrometer (Thorlabs, CCS200). The gaseous product was analysed by a quadrupole mass spectrometer (Hiden, HPR-20) equipped with a Faraday cup detector. The detection limit of the mass spectrometer is $\sim 0.001 \%$ conversion of $\mathrm{CO}_{2}$. The reactions were all operated in the low-conversion and light-controlled regime. For each temperature and light intensity condition, at least 15 min elapsed before reaching steady state and seven sequential measurements were made to determine the steady-state concentration of each gas and the associated reaction rates and uncertainties. The 15 atomic mass unit (amu) signal was used to quantify the methane production rate. The $28 \mathrm{amu}$ signal was used to quantify the carbon monoxide production rate, from which the background from carbon dioxide feedstock was subtracted. Deuterium $\left(\mathrm{D}_{2}\right.$, Sigma Aldrich, $99.8 \%$ atom D) was used in place of $\mathrm{H}_{2}$ for the isotopic labelling experiments.

DFT calculations. All calculations in this work were performed with the Vienna $\mathrm{Ab}$ initio Simulation Package (VASP) ${ }^{66}$. The Perdew-Burke-Ernzerhof (PBE) ${ }^{67}$ exchange-correlation functional was used along with its corresponding projected augmented wave (PAW) pseudopotentials. The semi-empirical D2 model ${ }^{68}$ was applied to describe the Van der Waals interactions. A plane-wave cutoff of $500 \mathrm{eV}$ was chosen. The Gamma centred $1 \times 2 \times 2 \mathrm{k}$-point was used for the structural relaxations (converged to $0.01 \mathrm{eV}^{-1}$ ), and $1 \times 8 \times 8$ for the projected LDOS calculations. Periodic boundary conditions were used in all three directions for the face-centred cubic $(f c c) \mathrm{Rh}$ model (Supplementary Fig. 7). A vacuum of $15 \AA$ was used in the $x$ direction to separate the $\mathrm{Rh}(100)$ surface slabs containing four layers of Rh atoms. In the $y$ and $z$ directions the lattice size for the supercell was chosen to be three times that of a unit cell. The adsorbed $\mathrm{CHO}$ and $\mathrm{CO}$ groups were placed on the exposed $\mathrm{Rh}(100)$ surface.

Material characterization. Transmission electron microscopy (TEM) images were collected by a FEI Tecnai $\mathrm{G}^{2}$ Twin operating at $200 \mathrm{kV}$. The TEM samples were prepared by dispersing the photocatalysts in ethanol with sonication and depositing on a copper grid coated with a carbon film (Ted Pella, 01813). Diffuse-reflectance ultraviolet-visible extinction spectra were obtained on an Agilent Cary 5,000 equipped with an external diffuse-reflectance accessory 
(DRA-2500). The composition of the photocatalysts was measured by a Kratos Analytical Axis Ultra X-Ray Photoelectron Spectrometer.

Data availability. The data that support this study are available from the corresponding authors on request.

\section{References}

1. Campbell, C. T., Parker, S. C. \& Starr, D. E. The effect of size-dependent nanoparticle energetics on catalyst sintering. Science 298, 811-814 (2002).

2. Hansen, T. W., DeLaRiva, A. T., Challa, S. R. \& Datye, A. K. Sintering of catalytic nanoparticles: particle migration or Ostwald ripening? Acc. Chem. Res. 46, 1720-1730 (2013).

3. Lewis, N. S. Toward cost-effective solar energy use. Science 315, 798-801 (2007).

4. Walter, M. G. et al. Solar water splitting cells. Chem. Rev. 110, 6446-6473 (2010).

5. Wang, W., Wang, S., Ma, X. \& Gong, J. Recent advances in catalytic hydrogenation of carbon dioxide. Chem. Soc. Rev. 40, 3703-3727 (2011).

6. Nichols, E. M. et al. Hybrid bioinorganic approach to solar-to-chemical conversion. Proc. Natl Acad. Sci. USA 112, 11461-11466 (2015).

7. Appl, M. Ammonia: Principles and Industrial Practice 65-176 (Wiley-VCH Verlag GmbH, 2007).

8. Habisreutinger, S. N., Schmidt-Mende, L. \& Stolarczyk, J. K. Photocatalytic reduction of $\mathrm{CO}_{2}$ on $\mathrm{TiO}_{2}$ and other semiconductors. Angew. Chem. Int. Ed. 52, 7372-7408 (2013).

9. Schneider, J. et al. Understanding $\mathrm{TiO}_{2}$ photocatalysis: mechanisms and materials. Chem. Rev. 114, 9919-9986 (2014).

10. Liu, C., Dasgupta, N. P. \& Yang, P. Semiconductor nanowires for artificial photosynthesis. Chem. Mater. 26, 415-422 (2014).

11. Lazar, M. A. \& Daoud, W. A. Achieving selectivity in $\mathrm{TiO}_{2}$-based photocatalysis. RSC Adv. 3, 4130-4140 (2013).

12. Thompson, T. L. \& Yates, J. T. Monitoring hole trapping in photoexcited $\mathrm{TiO}_{2}(110)$ using a surface photoreaction. J. Phys. Chem. B 109, 18230-18236 (2005).

13. Kazuhito, Hashimoto, Hiroshi, Irie \& Akira, Fujishima $\mathrm{TiO}_{2}$ photocatalysis: a historical overview and future prospects. Jpn. J. Appl. Phys. 44, 8269 (2005).

14. Mukherjee, S. et al. Hot electrons do the impossible: plasmon-induced dissociation of $\mathrm{H}_{2}$ on Au. Nano Lett. 13, 240-247 (2013).

15. Mukherjee, S. et al. Hot-electron-induced dissociation of $\mathrm{H}_{2}$ on gold nanoparticles supported on $\mathrm{SiO}_{2}$. J. Am. Chem. Soc. 136, 64-67 (2014).

16. Zhou, L. et al. Aluminum nanocrystals as a plasmonic photocatalyst for hydrogen dissociation. Nano Lett. 16, 1478-1484 (2016).

17. Christopher, P., Xin, H. \& Linic, S. Visible-light-enhanced catalytic oxidation reactions on plasmonic silver nanostructures. Nat. Chem. 3, 467-472 (2011).

18. Christopher, P., Xin, H., Marimuthu, A. \& Linic, S. Singular characteristics and unique chemical bond activation mechanisms of photocatalytic reactions on plasmonic nanostructures. Nat. Mater. 11, 1044-1050 (2012).

19. Marimuthu, A., Zhang, J. \& Linic, S. Tuning selectivity in propylene epoxidation by plasmon mediated photo-switching of $\mathrm{Cu}$ oxidation state. Science 339, 1590-1593 (2013).

20. Mubeen, S. et al. An autonomous photosynthetic device in which all charge carriers derive from surface plasmons. Nat. Nanotechnol. 8, 247-251 (2013).

21. Robatjazi, H., Bahauddin, S. M., Doiron, C. \& Thomann, I. Direct plasmondriven photoelectrocatalysis. Nano Lett. 15, 6155-6161 (2015).

22. Upadhye, A. A. et al. Plasmon-enhanced reverse water gas shift reaction over oxide supported Au catalysts. Catal. Sci. Technol. 5, 2590-2601 (2015).

23. Boerigter, C., Campana, R., Morabito, M. \& Linic, S. Evidence and implications of direct charge excitation as the dominant mechanism in plasmon-mediated photocatalysis. Nat. Commun. 7, 10545 (2016).

24. Boerigter, C., Aslam, U. \& Linic, S. Mechanism of charge transfer from plasmonic nanostructures to chemically attached materials. ACS Nano 10, 6108-6115 (2016).

25. Wu, B. et al. Plasmon-mediated photocatalytic decomposition of formic acid on palladium nanostructures. Adv. Opt. Mater. 4, 1041-1046 (2016).

26. Xiao, Q. et al. Alloying gold with copper makes for a highly selective visiblelight photocatalyst for the reduction of nitroaromatics to anilines. ACS Catal. 6, 1744-1753 (2016).

27. Sarina, S. et al. Enhancing catalytic performance of palladium in gold and palladium alloy nanoparticles for organic synthesis reactions through visible light irradiation at ambient temperatures. J. Am. Chem. Soc. 135, 5793-5801 (2013).

28. Swearer, D. F. et al. Heterometallic antenna - reactor complexes for photocatalysis. Proc. Natl Acad. Sci. USA 113, 8916-8920 (2016).

29. Sarina, S., Waclawik, E. R. \& Zhu, H. Photocatalysis on supported gold and silver nanoparticles under ultraviolet and visible light irradiation. Green Chem. 15, 1814-1833 (2013).
30. Olsen, T. \& Schiøtz, J. Origin of power laws for reactions at metal surfaces mediated by hot electrons. Phys. Rev. Lett. 103, 238301 (2009).

31. Knight, M. W., Sobhani, H., Nordlander, P. \& Halas, N. J. Photodetection with active optical antennas. Science 332, 702-704 (2011).

32. Brongersma, M. L., Halas, N. J. \& Nordlander, P. Plasmon-induced hot carrier science and technology. Nat. Nanotechnol. 10, 25-34 (2015).

33. Narang, P., Sundararaman, R. \& Atwater, H. A. Plasmonic hot carrier dynamics in solid-state and chemical systems for energy conversion. Nanophotonics $\mathbf{5}$, 96-111 (2016).

34. Demichel, O. et al. Dynamics, efficiency, and energy distribution of nonlinear plasmon-assisted generation of hot carriers. ACS Photonics 3, 791-795 (2016).

35. Brown, A. M. et al. Nonradiative plasmon decay and hot carrier dynamics: effects of phonons, surfaces, and geometry. ACS Nano 10, 957-966 (2016).

36. Watanabe, K., Menzel, D., Nilius, N. \& Freund, H.-J. Photochemistry on metal nanoparticles. Chem. Rev. 106, 4301-4320 (2006).

37. Kale, M. J., Avanesian, T., Xin, H., Yan, J. \& Christopher, P. Controlling catalytic selectivity on metal nanoparticles by direct photoexcitation of adsorbate-metal bonds. Nano Lett. 14, 5405-5412 (2014).

38. Zhang, X. et al. Size-tunable rhodium nanostructures for wavelength-tunable ultraviolet plasmonics. Nanoscale Horiz. 1, 75-80 (2016).

39. Watson, A. M. et al. Rhodium nanoparticles for ultraviolet plasmonics. Nano Lett. 15, 1095-1100 (2015).

40. Alcaraz de la Osa, R. et al. Rhodium tripod stars for UV plasmonics. J. Phys. Chem. C 119, 12572-12580 (2015).

41. Sanz, J. M. et al. UV plasmonic behavior of various metal nanoparticles in the near- and far-field regimes: geometry and substrate effects. J. Phys. Chem. C 117, 19606-19615 (2013)

42. Zettsu, N. et al. Synthesis, stability, and surface plasmonic properties of rhodium multipods, and their use as substrates for surface-enhanced raman scattering. Angew. Chem. Int. Ed. 45, 1288-1292 (2006).

43. Ren, B. et al. Surface-enhanced raman scattering in the ultraviolet spectral region: UV-SERS on rhodium and ruthenium electrodes. J. Am. Chem. Soc. 125, 9598-9599 (2003).

44. Xie, S., Liu, X. Y. \& Xia, Y. Shape-controlled syntheses of rhodium nanocrystals for the enhancement of their catalytic properties. Nano Res. 8, 82-96 (2015).

45. Yuan, Y., Yan, N. \& Dyson, P. J. Advances in the rational design of rhodium nanoparticle catalysts: control via manipulation of the nanoparticle core and stabilizer. ACS Catal. 2, 1057-1069 (2012).

46. Chambers, M. B. et al. Photocatalytic carbon dioxide reduction with rhodiumbased catalysts in solution and heterogenized within metal-organic frameworks. ChemSusChem 8, 603-608 (2015).

47. Avanesian, T., Gusmão, G. S. \& Christopher, P. Mechanism of $\mathrm{CO}_{2}$ reduction by $\mathrm{H}_{2}$ on $\mathrm{Ru}(0001)$ and general selectivity descriptors for late-transition metal catalysts. J. Catal. 343, 86-96 (2016).

48. Linic, S., Aslam, U., Boerigter, C. \& Morabito, M. Photochemical transformations on plasmonic metal nanoparticles. Nat. Mater. 14, 567-576 (2015).

49. Christensen, N. E. The band structure of rhodium and its relation to photoemission experiments. Phys. Status Solidi 55, 117-127 (1973).

50. Haruta, M. Copper, silver and gold in catalysis size- and support-dependency in the catalysis of gold. Catal. Today 36, 153-166 (1997).

51. Solymosi, F., Erdöhelyi, A. \& Bánsági, T. Methanation of $\mathrm{CO}_{2}$ on supported rhodium catalyst. J. Catal. 68, 371-382 (1981).

52. Sexton, B. A. \& Somorjai, G. A. The hydrogenation of $\mathrm{CO}$ and $\mathrm{CO}_{2}$ over polycrystalline rhodium: correlation of surface composition, kinetics and product distributions. J. Catal. 46, 167-189 (1977).

53. Matsubu, J. C., Yang, V. N. \& Christopher, P. Isolated metal active site concentration and stability control catalytic $\mathrm{CO}_{2}$ reduction selectivity. J. Am. Chem. Soc. 137, 3076-3084 (2015).

54. Karelovic, A. \& Ruiz, P. Mechanistic study of low temperature $\mathrm{CO}_{2}$ methanation over $\mathrm{Rh} / \mathrm{TiO}_{2}$ catalysts. J. Catal. 301, 141-153 (2013).

55. Jacquemin, M., Beuls, A. \& Ruiz, P. Catalytic production of methane from $\mathrm{CO}_{2}$ and $\mathrm{H}_{2}$ at low temperature: insight on the reaction mechanism. Catal. Today 157, 462-466 (2010)

56. Williams, K. J., Boffa, A. B., Salmeron, M., Bell, A. T. \& Somorjai, G. A. The kinetics of $\mathrm{CO}_{2}$ hydrogenation on a $\mathrm{Rh}$ foil promoted by titania overlayers. Catal. Lett. 9, 415-426 (1991).

57. Henderson, M. A. \& Worley, S. D. An infrared study of the hydrogenation of carbon dioxide on supported rhodium catalysts. J. Phys. Chem. 89, 1417-1423 (1985).

58. Goodman, D. W., Peebles, D. E. \& White, J. M. $\mathrm{CO}_{2}$ dissociation on rhodium: measurement of the specific rates on $\mathrm{Rh}(111)$. Surf. Sci. Lett. 140, L239-L243 (1984).

59. Dietz, L., Piccinin, S. \& Maestri, M. Mechanistic Insights into $\mathrm{CO}_{2}$ activation via reverse water-gas shift on metal surfaces. J. Phys. Chem. C 119, 4959-4966 (2015).

60. Yang, X. et al. Low pressure $\mathrm{CO}_{2}$ hydrogenation to methanol over gold nanoparticles activated on a $\mathrm{CeO}_{x} / \mathrm{TiO}_{2}$ interface. J. Am. Chem. Soc. 137, 10104-10107 (2015) 
61. Shi, H. \& Stampfl, C. First-principles investigations of the structure and stability of oxygen adsorption and surface oxide formation at $\mathrm{Au}(111)$. Phys. Rev. B 76, 075327 (2007).

62. Govorov, A. O. \& Richardson, H. H. Generating heat with metal nanoparticles. Nano Today 2, 30-38 (2007).

63. Baffou, G., Quidant, R. \& García de, A. F. J. Nanoscale control of optical heating in complex plasmonic systems. ACS Nano 4, 709-716 (2010).

64. Zhang, Z. L., Kladi, A. \& Verykios, X. E. Effects of carrier doping on kinetic parameters of $\mathrm{CO}_{2}$ hydrogenation on supported rhodium catalysts. J. Catal. 148, 737-747 (1994).

65. Hammer, B. \& Norskov, J. K. Why gold is the noblest of all the metals. Nature 376, 238-240 (1995).

66. Kresse, G. \& Furthmüller, J. Efficient iterative schemes for $a b$ initio total-energy calculations using a plane-wave basis set. Phys. Rev. B 54, 11169-11186 (1996).

67. Perdew, J. P., Burke, K. \& Ernzerhof, M. Generalized gradient approximation made simple. Phys. Rev. Lett. 77, 3865-3868 (1996).

68. Grimme, S. Semiempirical GGA-type density functional constructed with a long-range dispersion correction. J. Comput. Chem. 27, 1787-1799 (2006).

\section{Acknowledgements}

This research is supported by the National Science Foundation (CHE-1565657) and the Army Research Office (Award W911NF-15-1-0320). X.Z. is supported by Katherine Goodman Stern fellowship from the Graduate School, Duke University. X.L. is supported by the Department of Defense (DoD) through the National Defense Science \& Engineering Graduate Fellowship (NDSEG) Program. D.Z., N.Q.S. and W.Y. are supported by the Center for the Computational Design of Functional Layered Materials, an Energy Frontier Research Center funded by the U.S. Department of Energy (DOE), Office of Science, Basic Energy Sciences (BES), under Award \# DE-SC0012575. We acknowledge helpful conversations about plasmonic photocatalysis with P. Christopher and N. Halas and thank A. Barreda, Y. Gutierrez, F. González and F. Moreno for the prior electromagnetic simulations, and $\mathrm{M}$. Therien and B. Langloss for the help with diffuse-reflectance extinction spectroscopy. We also acknowledge the support from Duke University SMIF (Shared Materials Instrumentation Facilities).

\section{Author contributions}

H.O.E. conceived the project with J.L., and X.Z., J.L. and H.O.E. devised and developed the experiment. X.Z. carried out experimental work and analysis, and X.L. contributed to the analysis of the data and proofread the manuscript. D.Z., N.Q.S. and W.Y. carried out the DFT calculations. All the authors wrote the manuscript. J.L. is the PhD advisor and H.O.E. is the co-advisor of X.Z. and X.L. W.Y. is the advisor of D.Z. and N.Q.S.

\section{Additional information}

Supplementary Information accompanies this paper at http://www.nature.com/ naturecommunications

Competing financial interests: The authors declare no competing financial interests.

Reprints and permission information is available online at http://npg.nature.com/ reprintsandpermissions/

How to cite this article: Zhang, X. et al. Product selectivity in plasmonic photocatalysis for carbon dioxide hydrogenation. Nat. Commun. 8, 14542 doi: 10.1038/ncomms 14542 (2017).

Publisher's note: Springer Nature remains neutral with regard to jurisdictional claims in published maps and institutional affiliations.

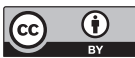

This work is licensed under a Creative Commons Attribution 4.0 International License. The images or other third party material in this article are included in the article's Creative Commons license, unless indicated otherwise in the credit line; if the material is not included under the Creative Commons license, users will need to obtain permission from the license holder to reproduce the material. To view a copy of this license, visit http://creativecommons.org/licenses/by/4.0/

(C) The Author(s) 2017 